\title{
Research on Enterprise Marketing Risk Evaluation Based on Group Decision and Grey System Theory
}

\author{
Ding Dechen ${ }^{1}$ \\ ${ }^{1}$ Associate Professor School of Insurance Shandong University of Finance and Economics Jinan 250014, China
}

\begin{abstract}
Traditional risk assessment methods have some defects to varying degrees. The marketing risk evaluation model based on heterozygous decision making and grey system theory applies multi-expert consultation mechanism to determine the weight of each evaluation index, and then the grey evaluation model is used to evaluate the marketing risk of enterprises. The case study shows that compared with other methods, this method not only effectively solves the problems of incomplete information, multiple evaluation indexes and collinearity of some indexes in the marketing risk evaluation of enterprises, but also easily finds the potential factors that lead to the marketing crisis.
\end{abstract}

\section{INTRODUCTION}

With the development of anti-globalization and the flood of world trade protectionism, the marketing environment of many enterprises has deteriorated sharply, and the marketing risks faced by enterprises have also increased accordingly. How to effectively evaluate the marketing risks faced by enterprises and then take effective measures to control marketing risks has become one of the hot issues in research. Risk assessment is traditionally classified in statistics. Most widely used evaluation methods at present, more is to use a particular aspect of information to evaluate risk, or ask for sample must be subjected to typical probability distribution assumption, or relying too heavily on the expert's experience, or need a lot of samples, so these methods have some shortcomings exist in different degrees, in practice it is difficult to find a suitable for all situations of enterprise marketing risk evaluation model ${ }^{[1-6]}$, are subject to certain restrictions in the evaluation practice. Therefore, the research on various mixed models that make full use of quantitative model and expert qualitative analysis has become more and more $\operatorname{popular}^{[7]}$. Grey system theory focuses on the "small sample" and "poor information" uncertainty problems which are difficult to be solved by probability statistics and fuzzy mathematics, and evaluates or predicts events by using sequence operators based on information coverage. Its characteristic is "minority data modeling"[8]. The advantage of grey system theory over fuzzy theory ${ }^{[9-}$ ${ }^{11]}$ is that grey theory considers fuzzy conditions, which means that grey theory can deal with a variety of fuzzy sets. In practice, due to the evaluation of enterprise marketing risk, it is a complex decision problem with incomplete information. Because many factors that affect the marketing risk evaluation results of enterprises cannot be quantified themselves, or the specific information of some factors cannot be fully obtained, there is a grey relationship between a variety of attributes and evaluation results. Therefore, compared with other methods, the advantages of grey system theory, such as the difference information principle and the non-uniqueness principle, are very suitable to solve the problems of incomplete information, many evaluation indexes and duplication among some indexes in the marketing risk evaluation of enterprises.

Based on this, this paper proposes an enterprise marketing risk evaluation model based on hybrid group decision making and grey system theory, applies multiexpert consultation mechanism to determine the weight of each evaluation index, and then uses grey evaluation model to evaluate enterprise marketing risk, and finally finds out the source of enterprise marketing risk.

\section{USE THE MULTI-EXPERT CONSULTATION MECHANISM TO DETERMINE THE WEIGHT OF INDICATORS}

Index weight is a key problem in the evaluation process. Analytic hierarchy process (AHP) is a common method to determine attribute weight. As for the multi-expert group decision making method, there are two commonly used methods to obtain group precedence, the personal Judgment aggregation method (AIJ) and the personal Priority discrimination method (AIP). In the actual evaluation instance, especially when its associated and qualitative index, policy makers are hard to identify a specific attribute weights or quantitative evaluation, using accurate numerical especially in qualitative attribute weights are unknown to group decision making problems, experts have a different view point of conflict is normal,

dechend@163.com 
even more than the use of several methods is limited. Therefore, this paper applies a multi-expert consultation mechanism ${ }^{[12]}$ to determine the weight of each index. The method mainly consists of two steps: attribute weight determination and comprehensive risk diagnosis, all of which rely on the judgment of several experts. Therefore, the qualitative attribute set is the foundation of the group decision-making process of the overall risk of the whole enterprise, and the attribute weight determination method and risk diagnosis method are its core contents.

\section{THE GREY EVALUATION OF ENTERPRISE MARKETING RISK}

\subsection{Design of grey hierarchy and white systematic weight function Sample}

The reliability of the evaluation result is directly related to the rationality of the design of the weight function of grey class and its whitening. In this paper, the marketing risk evaluation results of enterprises are divided into five grey levels: excellent (with the least risk possibility), inferior (with the least risk possibility), good (with the least risk possibility), medium (with the greatest risk possibility), and poor (with the greatest risk possibility), and their order is expressed by $\tau=\{1,2,3,4,5\}$ in turn. The grey number of the first grey level is designed as $\otimes_{1} \in[0,40]$, and the white systematic weight function is $f_{1}$. That is, when the expert ${ }^{E_{j}}$ 's evaluation value of the probability percentage of the evaluation result $d_{i l j}$ caused by the factors listed in a certain final indicator is within the range of $[0,20 \%]$, the membership degree of the probability degree of the evaluation result caused by the factors belonging to the first grey category (with the least possibility) should be 1 ; When ${ }^{d_{i j}}$ is within the range of $[20 \%, 40 \%]$, the membership degree of the first grey category (least likely) caused by this factor should be negatively correlated with; When ${ } d_{i j}$ is within the range of $[40 \%, 100 \%]$, the membership degree of the first grey category (least likely) in which the probability of the evaluation result is caused by this factor should be 0 . Similarly, the grey number and whitening weight functions of the second to fifth grey classes can be similarly set and interpreted.

The grey number of the second grey level is designed as $\otimes_{2} \in[20,55]$ and the white systematic weight function is $f_{2}$.The grey number of the third grey level is designed as $\otimes_{3} \in[40,65]$ and the white systematic weight function is $f_{3}$.The grey number of the fourth grey level is designed as $\otimes_{4} \in[55,85]$ and the white systematic weight function is $f_{4}$. The grey number of the fifth grey level is designed as $\otimes_{5} \in[65,100]$ and the white systematic weight function is $f_{5}$.

$$
\begin{aligned}
& f_{1}=\left\{\begin{array}{cc}
1, & 0 \leq d_{i l j} \leq 20 \\
\frac{40-d_{i l j}}{20}, & 20 \leq d_{i l j} \leq 40 \\
0, & 40 \leq d_{i l j} \leq 100
\end{array}\right. \\
& f_{2}=\left\{\begin{array}{cc}
\frac{d_{i l j}-20}{20}, & 20 \leq d_{i l j} \leq 40 \\
\frac{55-d_{i l j}}{15}, & 55 \leq d_{i l j} \leq 55
\end{array}\right. \\
& f_{3}=\left\{\begin{array}{cc}
0, & 0 \leq d_{i l j} \leq 40 \\
0, & 40 \leq d_{i l j} \leq 55 \\
\frac{d_{i l j}-40}{15}, & 55 \leq d_{i l j} \leq 65
\end{array}\right. \\
& f_{5}=\left\{\begin{array}{cc}
\frac{65 d_{i l j}}{10}, & 65 \leq d_{i l j} \leq 100 \\
0, & 0 \leq d_{i l j} \leq 55
\end{array}\right. \\
& f_{4}=\left\{\begin{array}{cc}
\frac{d_{i l j}-65}{20}, & 65 \leq d_{i l j} \leq 85 \\
0, & 85 d_{i l j} \leq 100 \\
\frac{d_{i l j}-55}{10}, & 55 \leq d_{i l j} \leq 65 \\
\frac{85-d_{i l j}}{20}, & 85 \leq d_{i l j} \leq 100 \\
0, &
\end{array}\right.
\end{aligned}
$$

\subsection{Grey evaluation of enterprise marketing risks}

For a particular secondary attribute $X_{\mathrm{ij}}$, the grey evaluation coefficient indicating that the secondary attribute should belong to the $\tau$ grey level is expressed by the grey evaluation coefficient $\theta_{\mathrm{i} t \tau}$, and their total evaluation coefficient is expressed by the grey evaluation coefficient $\theta_{i l}$. On the basis of expert judgment, their calculation formula is as follows:

$$
\begin{gathered}
\theta_{\mathrm{i} 1 \tau}=\sum_{j=1}^{k} f_{\tau}\left(d_{i l j}\right) \\
\theta_{i l}=\sum_{\tau=1}^{5} \theta_{i l \tau}
\end{gathered}
$$

Te grey evaluation coefficient ${ }^{\sigma_{i l} \tau}$, which indicates that the second-level attribute ${ }^{X_{\mathrm{ij}}}$ should belong to the $\tau$ grey level, is expressed as follows:

$$
\sigma_{\mathrm{i} 1 \tau}=\frac{\theta_{\mathrm{i} 1 \tau}}{\theta_{\mathrm{i} 1}}
$$

For the first-level attribute ${ }^{X_{i}}$, the corresponding grey evaluation weights of the $h(i)$ second-level attributes belonging to the five-level attribute ${ }^{X_{i}}$ constitute the grey evaluation weight matrix of ${ }^{X_{i}}$, which is represented by $W_{i}$ :

$$
W_{i}=\left[\sigma_{i l \tau}\right]_{h(i) \times 5}
$$

Suppose the weight vector of the $h(i)$ secondary attributes belonging to attribute ${ }^{X_{i}}$ of the five levels is 
expressed as $O_{i}=\left[\begin{array}{ll}o_{\mathrm{i} 1}, & \mathrm{o}_{\mathrm{i} 2}, \ldots, \mathrm{O}_{\mathrm{ih}(\mathrm{i})}\end{array}\right]$, which can be obtained through the multi-expert negotiation mechanism. The grey manual evaluation vector calculation formula of first-order attribute $X_{i}$ is as follows:

$$
B_{i}=O_{i} \times W_{i}=\left[b_{i 1}, b_{i 2}, b_{i 3}, b_{i 4}, b_{i 5}\right]
$$

All the grey artificial evaluation vectors of first-level attribute $X_{i}$ constitute the grey evaluation weight matrix of the probability of the evaluation result of the marketing risk of the enterprise, which is represented by $W$, as shown in Formula (10). Similarly, the weight vector of the first-order attribute is expressed as $O=\left[\begin{array}{lll}o_{1}, & \mathrm{o}_{2}, \ldots, & \mathrm{o}_{h}\end{array}\right]$, which can also be obtained by the procedure in 2 . The final weight vector of grey manual evaluation for the possibility of evaluation results can be calculated as follows:
$B=O \times W=\left[b_{1}, b_{2}, b_{3}, b_{4}, b_{5}\right]$

Finally, the probability of marketing risk evaluation results can be ranked according to the weight vector.

\section{CAse study}

\subsection{Establishment of evaluation index system}

The evaluation index system is the foundation to consider the marketing risk of enterprises. By referring to the research of relevant scholars ${ }^{[2][5][13]}$, the enterprise marketing risk evaluation index system is established, as shown in Table I.

\begin{tabular}{|c|c|c|c|}
\hline \multirow{3}{*}{$\begin{array}{l}\text { First level indicator } \\
\text { Political and legal } \\
\text { environmental risks }\end{array}$} & \multirow{3}{*}{$\mathrm{x}_{1}$} & \multicolumn{2}{|l|}{ Secondary indicator } \\
\hline & & Policy risk & $\mathrm{x}_{11}$ \\
\hline & & The legal risks & $\mathrm{x}_{12}$ \\
\hline \multirow{4}{*}{$\begin{array}{l}\text { Economic } \\
\text { environmental risk } \\
\text { Science and technology } \\
\text { environmental risks }\end{array}$} & \multirow[t]{2}{*}{$\mathrm{x}_{2}$} & The level of economic development risks & $x_{21}$ \\
\hline & & Risk of economic fluctuations & $\mathrm{X}_{22}$ \\
\hline & $\mathrm{x}_{3}$ & New technology risks & $\mathrm{x}_{31}$ \\
\hline & & The speed of technological change risks & $\mathrm{x}_{32}$ \\
\hline \multirow{3}{*}{$\begin{array}{l}\text { Socio-cultural and } \\
\text { environmental risks }\end{array}$} & \multirow{3}{*}{$\mathrm{x}_{4}$} & Material cultural risk & $\mathrm{x}_{41}$ \\
\hline & & Religious risk & $\mathrm{x}_{42}$ \\
\hline & & Language risk & $\mathrm{x}_{43}$ \\
\hline \multirow{2}{*}{$\begin{array}{l}\text { Natural environmental } \\
\text { risk }\end{array}$} & & Risk of natural resource shortage & $\mathrm{x}_{51}$ \\
\hline & & Natural environmental protection risks & $\mathrm{X}_{52}$ \\
\hline \multirow[t]{3}{*}{ Market selection risk } & \multirow{3}{*}{$\mathrm{x}_{6}$} & Market segmentation risk & $\mathrm{x}_{61}$ \\
\hline & & Target customer selection risk & $\mathrm{x}_{62}$ \\
\hline & & Market positioning risk & $\mathrm{x}_{63}$ \\
\hline \multirow[t]{4}{*}{ Marketing strategy risk $\mathrm{x}$} & \multirow[t]{4}{*}{$\mathrm{x}_{7}$} & The product risk & $\mathrm{X}_{71}$ \\
\hline & & Price risk & $\mathrm{x}_{72}$ \\
\hline & & Promotion risk & $\mathrm{x}_{73}$ \\
\hline & & Channel risk & $\mathrm{x}_{74}$ \\
\hline \multirow{5}{*}{\multicolumn{2}{|c|}{ Market competition risk $\mathrm{x}_{8}$}} & Customer risk & $\mathrm{X}_{81}$ \\
\hline & & Substitution risk & $\mathrm{X}_{82}$ \\
\hline & & Supplier risk & $\mathrm{x}_{83}$ \\
\hline & & Competitor risk & $\mathrm{X}_{84}$ \\
\hline & & Potential entrant risk & $\mathrm{X}_{85}$ \\
\hline \multirow{3}{*}{\multicolumn{2}{|c|}{$\begin{array}{l}\text { Marketing organizations } \mathrm{x} \\
\text { manage risk }\end{array}$}} & Marketing organizational structure risk $\mathrm{x}$ & $\mathrm{X}_{91}$ \\
\hline & & Marketing organization system risk & $\mathrm{X}_{92}$ \\
\hline & & Marketing staff risk & $\mathrm{X}_{93}$ \\
\hline
\end{tabular}

\subsection{Calculation of index weight}

Taking the evaluation of marketing risk of a large manufacturing enterprise in China as an example, the proposed model is applied to study. Firstly, a panel of 5 experts is formed to evaluate each index in the index system by single factor. Each expert gives the importance of each level of indicators and the probability that each indicator will lead to the evaluation result. The scoring interval of the importance of the first-level indicators is shown in Table II, while the scoring interval of the second-level indicators is slightly.

Table II. Importance score range of first-level indicators

\begin{tabular}{|l|c|c|c|c|c|}
\hline & $e_{1}$ & $e_{2}$ & $e_{3}$ & $e_{4}$ & $e_{5}$ \\
\hline$X_{1}$ & {$[0.5,0.7]$} & {$[0.4,0.7]$} & {$[0.4,0.6]$} & {$[0.7,0.9]$} & {$[0.6,0.7]$} \\
\hline$X_{2}$ & {$[0.2,0.4]$} & {$[0.1,0.4]$} & {$[0.3,0.5]$} & {$[0.5,0.7]$} & {$[0.3,0.5]$} \\
\hline$X_{3}$ & {$[0.2,0.3]$} & {$[0.2,0.3]$} & {$[0.2,0.4]$} & {$[0.4,0.5]$} & {$[0.4,0.5]$} \\
\hline$X_{4}$ & {$[0.7,1.0]$} & {$[0.6,0.9]$} & {$[0.8,1.0]$} & {$[0.7,1.0]$} & {$[0.8,0.9]$} \\
\hline$X_{5}$ & {$[0.5,0.6]$} & {$[0.7,0,8]$} & {$[0.6,0.8]$} & {$[0.6,0.9]$} & {$[0.5,0.8]$} \\
\hline$X_{6}$ & {$[0.3,0.7]$} & {$[0.4,0.5]$} & {$[0.5,0.6]$} & {$[0.8,0.9]$} & {$[0.6,0.8]$} \\
\hline
\end{tabular}




\begin{tabular}{|l|l|l|l|l|l|}
\hline$X_{7}$ & {$[0.3,0.4]$} & {$[0.2,0.3]$} & {$[0.3,0.6]$} & {$[0.6,0.7]$} & {$[0.4,0.5]$} \\
\hline$X_{8}$ & {$[0.2,0.5]$} & {$[0.1,0.3]$} & {$[0.2,0.5]$} & {$[0.3,0.5]$} & {$[0.4,0.6]$} \\
\hline$X_{9}$ & {$[0.6,1.0]$} & {$[0.6,0.7]$} & {$[0.8,0.9]$} & {$[0.9,1.0]$} & {$[0.8,0.9]$} \\
\hline
\end{tabular}

According to the expert consultation mechanism, the weight of the first-level index is

$W_{X}=(0.0857,0.1160,0.1361,0.0109,0.0670,0.1761,0.1248,0.1020,0.1814)$

The weight of each 2 class index is omitted.

\subsection{Gray evaluation}

According to formula (6) and formula (7), the grey evaluation coefficient and the total grey evaluation coefficient of each index can be calculated. According to formula (8), the gray evaluation coefficient of each second-level index ${ }^{X_{i j}}$ belonging to the $\tau$ gray level can be obtained.

According to the data above and formula (10), $B_{i}$ can be obtained, and according to formula (11), the final weight vector $B$ of gray evaluation can be obtained, as shown in Table III.

Table III. Each level attribute and the final grey evaluation vector

\begin{tabular}{|l|l|l|l|l|l|}
\hline & $\begin{array}{l}\text { Minimum } \\
\text { risk }\end{array}$ & $\begin{array}{l}\text { Bigger } \\
\text { risks }\end{array}$ & $\begin{array}{l}\text { Medium } \\
\text { risk }\end{array}$ & $\begin{array}{l}\text { Greater } \\
\text { risk }\end{array}$ & $\begin{array}{l}\text { Biggest } \\
\text { risk }\end{array}$ \\
\hline $\mathrm{X}_{1}$ & 0.3379 & 0.3551 & 0.1070 & 0 & 0 \\
\hline $\mathrm{X}_{2}$ & 0.2722 & 0.7760 & 0.1518 & 0 & 0 \\
\hline $\mathrm{X}_{3}$ & 0.1252 & 0.3415 & 0.3796 & 0.0537 & 0 \\
\hline $\mathrm{X}_{4}$ & 0.6250 & 0.3750 & 0 & 0 & 0 \\
\hline $\mathrm{X}_{5}$ & 0.2167 & 0.5500 & 0.1333 & 0 & 0 \\
\hline $\mathrm{X}_{6}$ & 0.3219 & 0.2498 & 0 & 0.1283 & 0 \\
\hline $\mathrm{X}_{7}$ & 0.2128 & 0.7431 & 0.1735 & 0.1706 & 0 \\
\hline $\mathrm{X}_{8}$ & 0.1287 & 0.8525 & 0.2188 & 0 & 0 \\
\hline $\mathrm{X}_{9}$ & 0.4285 & 0.5327 & 0 & 0.0388 & 0 \\
\hline $\mathrm{FD}$ & 0.3543 & 0.5167 & 0.1121 & 0.0078 & 0 \\
\hline
\end{tabular}

\subsection{Conclusion}

As shown in Table III, according to the results of gray evaluation and the principle of maximum optimal decision weight, the marketing risk evaluation result of the enterprise is sub-optimal. This conclusion is mainly obtained from, and, and the potential risk factors include and. Specifically speaking, there are three direct sources of marketing risks for the enterprise at present. The macro environment is the economic environment risk, the micro environment is the marketing strategy risk and market competition risk, and the potential risk is the natural environment risk and the marketing organization management risk. Therefore, in order to cope with the risks caused by the economic environment and the natural environment, enterprises must actively improve their marketing organization management, adjust their marketing strategies, and seriously deal with the increasingly fierce market competition.

\section{SUMMARY AND PROSPECT}

The evaluation of enterprise marketing risk is a complex decision problem with incomplete information. Because many factors that affect the marketing risk evaluation results of enterprises cannot be quantified themselves, or the specific information of some factors cannot be fully obtained, there is a grey relationship between a variety of attributes and evaluation results. Most of the evaluation methods widely used at present either require samples to obey the hypothesis of typical probability distribution, or rely too much on the experience of experts, or need a large number of samples, so these methods have some defects to varying degrees, and will be subject to certain limitations in the evaluation practice. In this paper, a model of marketing risk evaluation based on heterozygous decision making and grey system theory is proposed, and the weight of each evaluation index is determined by multi-expert consultation mechanism, and then the grey evaluation model is used to evaluate the marketing risk of enterprises. The case study shows that, compared with other methods, this method not only effectively solves the problems of incomplete information, many evaluation indexes, and duplication among some indexes, but also easily finds the factors that may lead to the marketing risk of enterprises. In the future, further research can be carried out to optimize the enterprise marketing risk evaluation index system.

\section{ACKNOWLEDGMENT}

I wish to thank the timely help given by Dr Wang Xingyuan, Professor of School of management, University of Shandong, for his help in analyzing the large number of samples and in interpreting the significance of the results of this study.

This research was financially supported by the scientific research project of National Natural Science Foundation of China (Grant No: 71272121) and the National Social Science Foundation of China (Grant No: 17BJL078)

\section{REFERENCES}

1. Rong Mei. Application of Fuzzy comprehensive Evaluation method in Marketing Risk Assessment [J]. Statistics and Decision-making, 2011 (7) :169171.

2. Ding Deshen, Wang Xingyuan. Research on enterprise marketing risk premonition based on BP neural network optimized by genetic algorithm [J]. East China Economic Management,2012(11):128-130.

3. Meng Qingyan. Research on marketing safety Risk Evaluation and Management System of Electric Power Companies [J]. China New Technology and New Products, 2014(22):57-60.

4. Sun Junfeng, Zhang Yunq,Li Jian.Progress Review of Enterprise Marketing Risk Management Theory[J].ECONOMY AND MANAGEMENT,2017 Vol.31 No.6,pp:77-83.

5. Shen Jinjin. Research on the Festival Marketing Risk Assessment of Platform A[D] Master's thesis of South China University of Technology,2018,pp:4-5. 
6. She Ichang, Li Minchang, Jhan Cyunliao. Risk factors of enterprise internal control under the internet of things governance: A qualitative research approach[J].Information \& Management 57 (2020) 103335,pp:1-18.

7. Kaihong Wang,Xu Yang,Yiwan Sun,and Chuan Ding.A Comparative Study of Marketing Channel Multiagent Stackelberg Model Based on Perfect Rationality and Fairness Preference[J].Abstract and Applied Analysis, vol. 2014, Article ID 527458, 11 pages, 2014. doi:10.1155/2014/527458.

8. Liu Sifeng, Yang Yingjie. Research Progress of Grey Systems (2004-2014)[J]. Journal of Nanjing University of Aeronautics and Astronautics,2015 (1) :1-18.

9. Yueru Ma and Lijun Peng.Coupled Model of Artificial Neural Network and Grey Model for Tendency Prediction of Labor Turnover[J]. Mathematical Problems in Engineering, vol. 2014, Article ID 918307, 6 pages, 2014. doi:10.1155/2014/918307.

10. Anton Bezuglov, Gurcan Comert .Short-term freeway traffic parameter prediction: Application of grey system theory models[J].Expert Systems With Applications 62 (2016) 284-292.

11. Shuwei Wanga, Peng Wanga, Yifei Zhanga. A prediction method for urban heat supply based on grey system theory[J].Sustainable Cities and Society 52 (2020) 101819,pp:1-7.

12. Wei Liang, Xiaolu Zhang, and Manfeng Liu.The Maximizing Deviation Method Based on IntervalValued Pythagorean Fuzzy Weighted Aggregating Operator for Multiple Criteria Group Decision Analysis[J].Discrete Dynamics in Nature and Society, vol. 2015, Article ID 746572, 15 pages, 2015. doi:10.1155/2015/746572.

13. Zhang Yunqi, Li Jun. Research on the Formation Mechanism of enterprise marketing Risk [J]. Management World,2009(3):178-179. 